\title{
Mass closure technique plus wound edges augmentation with two longitudinal subcutaneous tubes for all ages and all incisions to avoid burst abdomen
}

\author{
Yasser Hussein, MD; Abd Elwahhab M Hamed, MD; \\ Wael Shelfa, MD; Hasan Awad, MD
}

\begin{abstract}
General Surgery Department, Zagazig University, Sharkiya, Egypt.
\end{abstract}
\begin{abstract}
Background: Burst abdomen and incisional herniation are continuing problems for the general surgeon. A prospective study was carried out to define the extent of the problem.

Patients and methods: The present study was carried out over a period of two years from September 2009 to September 2011 in Zagazig University Hospital, Surgery Department and included 50 patients for various intra-abdominal conditions both in emergency and routine cases. Such cases were included the high risk group for developing burst abdomen.

Results: Eighty percent of our patients belonged to the high risk group. Postoperatively, none of the patients developed burst abdomen. One case developed incisional hernia. Superficial wound infection was noticed in 5 cases.

Conclusion: This method of abdominal closure resulted in zero percent incidence of burst abdomen in spite of the presence of predisposing factors for burst abdomen.
\end{abstract}

\section{Introduction:}

Burst abdomen is a serious postoperative complication that concerns every abdominal surgeon. Efforts have been made to overcome this complication with various innovations in the technique of closure of laparotomy incisions and use of different types of suture materials.

Some authers published that there was a high incidence of wound dehiscence (3.88 to $14 \%)^{5,9}$ after multilayer closure of abdominal incisions with catgut sutures. In the other aspect, recent experimental and clinical studies have reported a significant reduction in the incidence of burst abdomen by using a single layer closure of laparotomy incisions with a non-absorbable suture material.

The incidence of burst abdomen with this technique varies from 0 to $0.9 \% .^{2,4,11,12}$ In some cases, skin cut through had occurred before the linea alba and rectus sheath healed strongly, especially in patients with increased intra-abdominal pressure and with high risk factors. Thus the logical answer is therefore to support the wound edges as a trial to avoid it. We tried to solve this problem through placing two SC plastic tubes.

Thus the purpose of the present study was to assess the efficacy of a mass closure technique of laparotomy incisions with interrupted monofilament polyprolyne sutures after wound edges augmentation with two subcutaneous tubes in the prevention and treatment of burst abdomen.

\section{Patients and methods:}

The present study was carried out over a period of two years from September 2009 to September 2011 and included 50 patients in Zagazig University Hospital, Surgery Department, operated on by the four authors for various intra abdominal conditions. Both emergency and routine cases were included and there was no patient selection. The patients 
were particularly assessed for the presence of factors responsible for delayed wound healing and burst abdomen, i.e. nutritional status, anaemia, hypoproteinaemia, pre- and postoperative prolonged steroid therapy, peritonitis, malignancy, presence of jaundice, uraemia, prolonged post-operative abdominal distension and persistent cough. Such cases were included in the high risk group for developing burst abdomen. 5,9

Post-operatively, each patient was examined for the presence or absence of any wound infection, extrusion of suture ends, sinus formation and development of burst abdomen. The diagnosis of burst abdomen was made when all the abdominal layers gave way. 5

\section{Technique:}

After completion of intraperitoneal procedure, First step was to make a small stab wound incision $(1 \mathrm{~cm})$ about two $\mathrm{cm}$ away from the wound edges in both sides to introduce the plastic tubes through subcutaneous tunneling using a long artery forceps Figure(1).

Second step; a deep seated suture picking up all layers including the skin was made. The parietal peritoneum, posterior rectus sheath, and the anterior rectus sheath were all approximated by a single layer of interrupted sutures of No. '1' monofilament polyprolyne, mounted on a large half circle, cutting needle. Each suture was placed 2 to $2.5 \mathrm{~cm}$ away from the wound edge including the plastic tubes on either side, at an interval of about $3 \mathrm{~cm}$ from each other. In the case of paramedian incision, rectus muscle was not included within the suture bite. To achieve this, while passing suture through the lateral cut edge of the incision, first the peritoneum and the posterior rectus sheath were pierced, then the medial border of the muscle was displaced laterally with the curve of the needle, before finally passing the suture through the anterior rectus sheath.

Interrupted sutures were taken in between the deep tension sutures with Vicryl suture 2/0 picking also all layers in one mass closure. The skin was closed as a separate layer with 3/0 silk sutures.

Age, weight, body build, site and type of incision, preoperative and postoperative complications, and the bacteriological findings in the wound and status of the surgeon who performed the wound closure were noted. The patients were reviewed at one, three, six, and 12 months, when the presence of any infection or wound herniation was carefully recorded.

Table (1): Preoperative patient's characters'.

\begin{tabular}{|ll|c|}
\hline Preoperative patients characters & \\
\hline \multirow{2}{*}{ Age: } & $1-20$ & $7(14 \%)$ \\
& $>20-40$ & $3(6 \%)$ \\
& $>40$ & $40(80 \%)$ \\
\hline sex: & Men & $40(80 \%)$ \\
& women & $10(20)$ \\
\hline Incision: & Midline & $37(74 \%$ \\
& Paramedian & $10(20 \%)$ \\
& Transverse & 3 \\
\hline Risk factors: & Obesity & 12 \\
& Uremia & 3 \\
& Cirrhosis & 20 \\
& Jaundiced & 2 \\
& Malignancy & 11 \\
& Diabetes & 30 \\
& Taking steroids & 4 \\
\hline
\end{tabular}


Table (2): Postoperative complications.

\begin{tabular}{|l|l|}
\hline Postoperative complications & No \\
\hline Wound infection & $5[10 \%]$ \\
Hematoma tube site & $3[6 \%]$ \\
Burst & 0 \\
Abdominal leakage [ascites] & 0 \\
Incisional hernia & $1(2 \%)$ \\
Wound discharge & $3[6 \%]$ \\
\hline Hospital stay & $3-7[6.3 \pm 3.2]$ days \\
\hline Operative time & 40 to $120(80.5 \pm 2.6$ minutes) \\
\hline
\end{tabular}

\section{Results:}

There were 50 patients, 40 males and 10 females. The age varied from 1 to 62 years with an average 44 years of age. 30 patients were operated on as elective cases, while 20 underwent an emergency laparotomy. The majority of cases were explored through a midline incision Table(1) Eighty percent of the patients belonged to high risk group for the development of the burst abdomen. Table(1) shows the list of predisposing causes present in these patients.

- None of the patients developed burst abdomen

- One case developed incisional hernia.

- Superficial wound infection was noticed in 5 cases. However, in all of them the wounds healed in due course of time, without requiring removal of the nylon sutures Table(2).

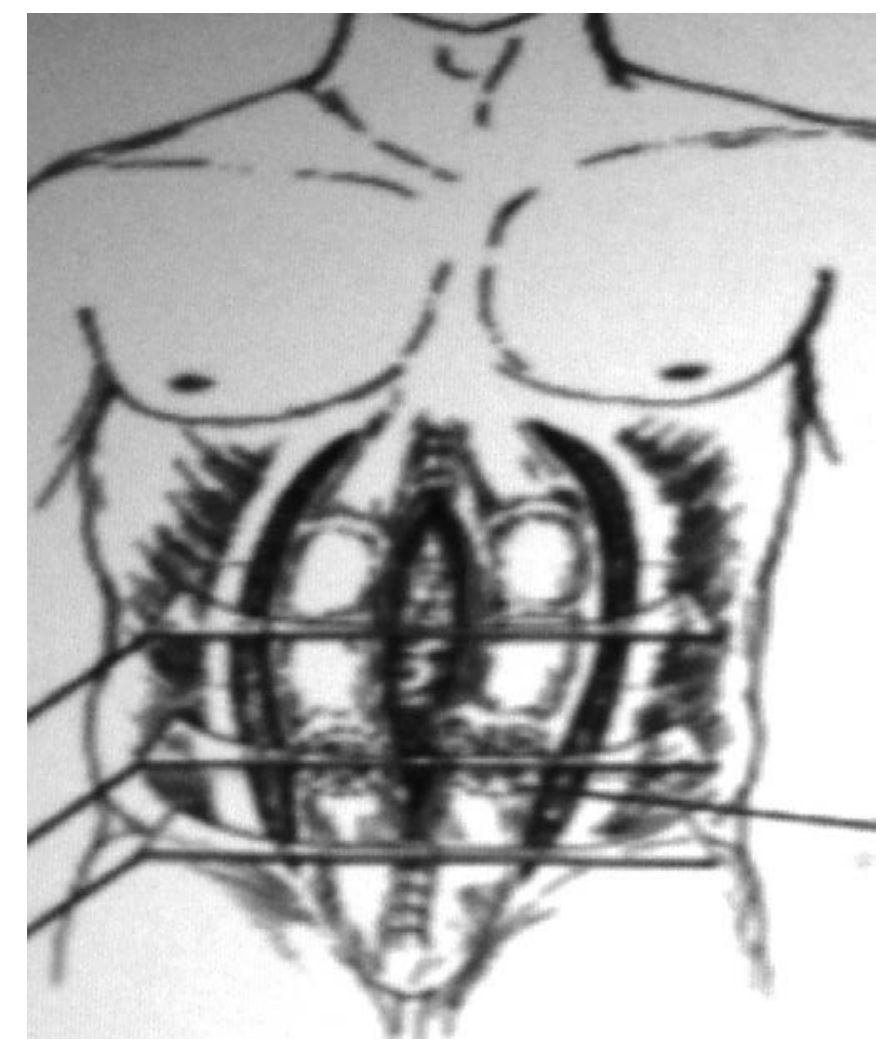

Figure (1): Diagram showing placing SC tubes at either wound edges. 


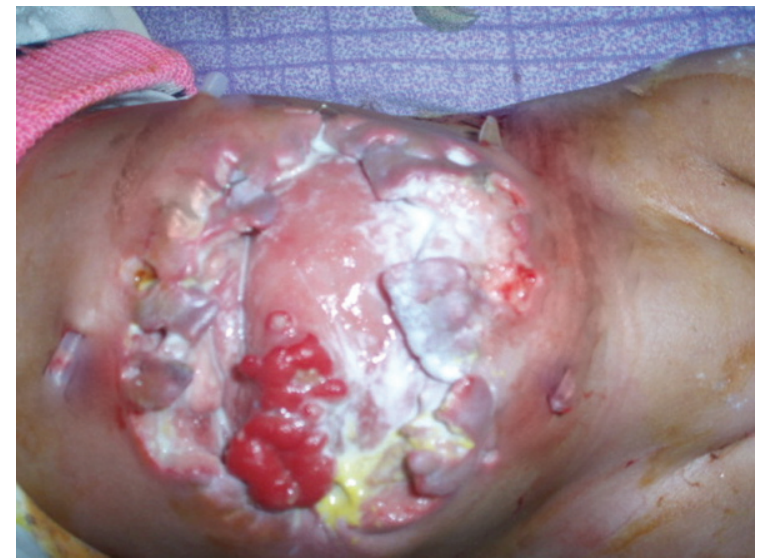

(a): During operation.

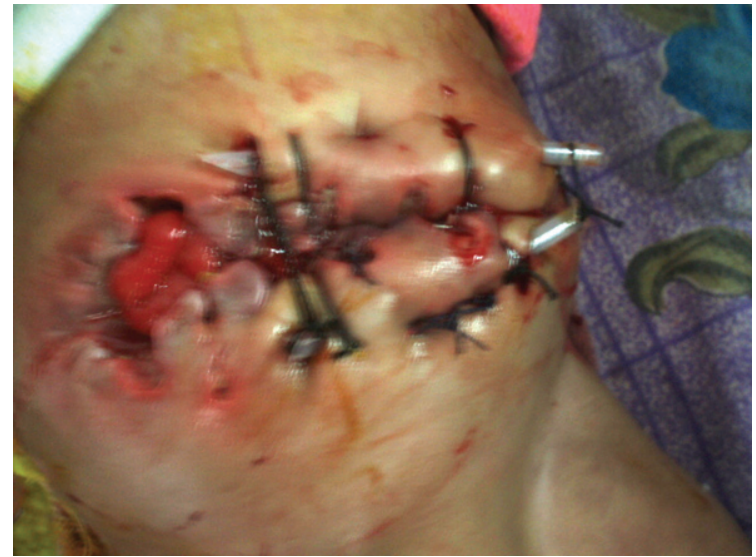

(b): After operation.

Figure (3): An infant with bust abdomen after exploration and colostomy in a transverse incision closed by our method. $(a, b)$

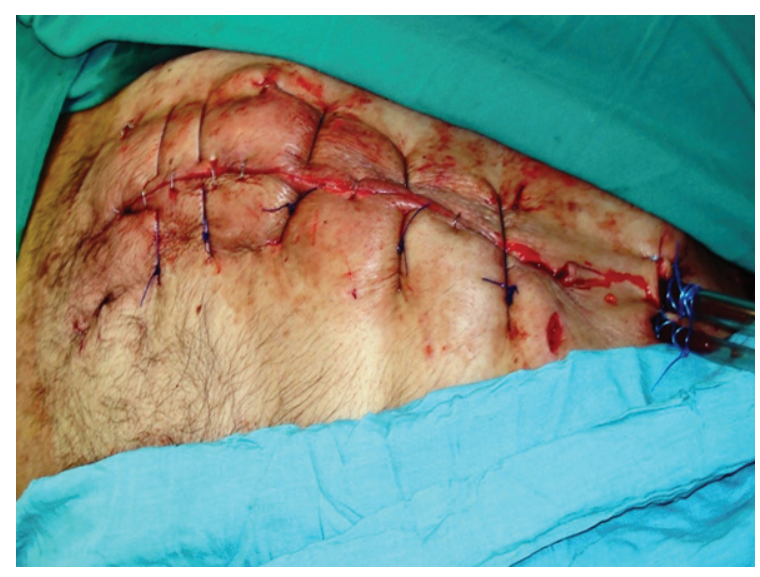

(a): During operation.

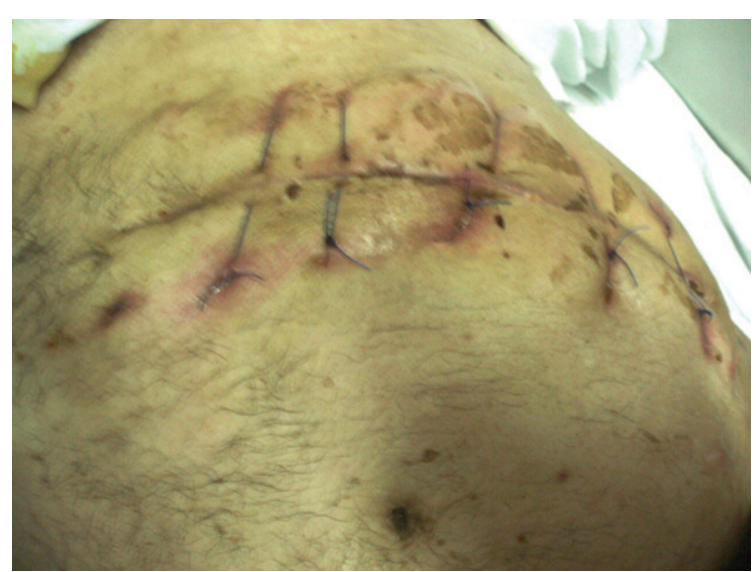

(b): After removal of tubes.

Figure (2): An edery patient 65 year after splenectomy due to malignancy in a subcostal incision closed by our method.(a,b)

\section{Discussion:}

The ideal method of abdominal wound closure has not been discovered. The ideal method should be technically so simple that the results are as good in the hands of the trainee as in those of the surgical master. It should be free from the complications of burst abdomen, incisional hernia, and persistent sinuses; it should be comfortable to the patient; and it should leave a reasonably aesthetic scar. ${ }^{11}$ Since 1975 a series of trials of different techniques of closure of abdominal incisions were conducted. $3,5,10,15$ We report here a modification trial for a mass closure technique to improve the results of abdominal closure. It is very much within the means of a surgeon to prevent the development of burst abdomen from taking place, even in the presence of predisposing factors responsible for poor wound healing (e.g. poor nutrition, cirrhosis of liver, uraemia, prolonged steroid therapy, infection and malignancy) and cutting through of suture material (post-operative paralytic ileus, and persistent cough). In our series we had various risk factors that threaten to burst abdomen and delay wound healing thus we advised to use a monofilament non-absorbable polypropylene sutures to overcome this risk factor. Marked reduction in the incidence of burst abdomen can be achieved by utilizing a proper suture material and by employing 
a correct technique of abdominal closure. From the above criteria, chromic catgut suture appears highly unsatisfactory for closure of laparotomy incisions. It loses its tensile strength very fast and little is left after 8-9 days. It gets prematurely absorbed. $1,4,14$ Jones et al. ${ }^{1}$ first reported the use of an interrupted mass far and-near suture technique and had only one burst abdomen in 81operations after steel closure. We had the same satisfactory results with no patients with burst abdomen after our technique. Goligher ${ }^{10}$ reported one burst abdomen and no hernias after 108 paramedian elective laparotomies using interrupted 28-gauge stainless steel wire sutures. Similar satisfactory results have been reported in our work without the use of stainless steel sutures, with no patients with burst abdomen. Using monofilament polypropylene suture, we decreased the incidence of late incisional herniation, in our series to $2 \%$. In other series by Pollock, ${ }^{3-4}$ Keill $^{6}$ and Blomstedt $^{7}$ the herniation rate was $11 \%$, using polyglycolic acid sutures, which is unacceptably high. Most of these wound failures occurred within the first three months and possibly result from the disappearance of the suture material before sufficient collagen has been laid down to restore intrinsic tensile strength. Polyglycolic acid loses over $90 \%$ of its strength within three weeks 8 whereas the abdominal wall fascia requires about 120 days to regain its strength. ${ }^{9}$ Versus The original technique of mass closure under the skin by Dudley (1970) ${ }^{16}$ showed that the tendency to cut through is inversely proportional to the size of the tissue bite. Thus smaller tissue bites have a higher incidence to cut through. Thus if we put an augmentation tube on either side of wound edges as our technique and making deep seated sutures picking all layers, we can avoid the risk of cut through and postoperative herniation or burst abdomen. Moreover, in our procedure the wound augmentation, even if a small bite of tissue by the suture still occurs, the distribution of forces will be distributed to the whole wound length not only the suture site. It offers enough support till healing is complete and avoids the process of cut through. Experimentally, it has been proved that the mean suture holding capacity of the anterior rectus sheath alone is just over half that of full thickness of the peritoneum, muscle and the aponeurosis. ${ }^{16}$ Agarwal et al, ${ }^{17}$ reported that closure of midline incision by reinforced tension line (RTL) on 90 patients resulted in no burst abdomen, the same satisfactory results have been reported in our work. The interrupted sutures were preferred over continuous sutures in the present study, as it was feared that continuous mass suture might produce strangulation of the tissues included in the bite. Though Jenkin (1976) $)^{5}$ has used continuous sutures with good results, he has recommended that a ratio of about 4:1 between the length of the suture material and the wound length should be maintained to avoid strangulation of the tissues. Conclusion: There was zero per cent incidence of burst abdomen in the present series despite the presence of predisposing factors in the majority of cases. The type of surgery, the basic disease, type of incision and age and sex of the patient did not affect the results.

\section{References:}

1- Jones TE, Newell ET, Brubaker RE: Use of alloy steel wire in closure of abdominal wounds. Surg Gynecol Obstet 1941; 72: 1056-1059.

2- cothren CC, Moore EE, Johnson Moore JB, GBurch JM: One hundred percent fascial approximation with sequential closure of the open abdomen. Am J surgery 2006; 192 (2): 238-242.

3- Pollock AV, Greenall MJ, Evans M: Singlelayer mass closure of major laparotomies by continuous suturing. $J R$ Soc Med 1979; 72: 889-893.

4- Pollock AV, Evns M: Early prediction of late incisional hernias. $\mathrm{Br} J$ Sur 1989; 76(9): 953-954.

5- Jenkin T P N: The burst abdominal wound: A mechanical approach. Brit J Surg 1976; 63: 873-876.

6- Keill RH, Kcitzer WF, Nichols WK, 
Hanzel J, DeWeese MS: Abdominal wound dehiscence. Arch Surg 1973; 106: 573-577.

7- Blomstedt B, Welin-Berger T: Incisional hernias. Acta Chir Scand 1972; 138: 275-278.

8- Leaper DJ, Pollock AV, Evans N: Abdominal wound closure. A trial of nylon, polyglycolic acid and steel sutures. Brit J Surg 1977; 64: 603-606.

9-Kirk R M: Effect of methods of opening and closing the abdomen on incidence of wound bursting. Lancet 1972; 2: 352-353.

10-Goligher JC, Irvin TT, Johnston D, De Dombal FT, Hill GL, Horrocks JC: A controlled clinical trial of 3 methods of closure of laparotomy wounds. $\mathrm{Br}$ Surg 1975; 62: 823-827.

11-Hodgson NC, Malthaner RA, Ostbye $\mathrm{T}$ : The search for an ideal method of abdominal fascial closure: A metaanalysis. Ann surg 2000; 231 (3): 436-442.

12-Van’t Riet M, Steyerberg EW, Nellensteyn J, Bonjer itJ, Jeekel J: Meta-analysis of techniques for closure of midline abdominal incisions. Br J surg 2002; 89 (11): 1350-1356.

13-Norris JD: A review of wound healing and the mechanics of dehiscence. Surgery 1939; 5: 775-786.

14-Postleth wait RW, schavble JF, Dillon HC, morgan J: An evaluation of surgical siture material. Surg Gynaecol \& Obstet 1959; 108: 555-566.

15-Israelsson LA, Jonsson T, Knutsson A: Suture technique and wound healing in midline laparotomy incisions. Eur J Surg 1996; 162 (8): 605-609.

16-Dudley HAF: Layered and mass closure of abdominal wall: A theoretical and experimental analysis. Br J Surg 1970; 57: 664-667.

17-Agarwal A, Hossain Z, Das A, Charkraborty S, Mitra N, Gupta M, Ray $\mathrm{U}$ : Reinforced tension line suture closure after midline laparotomy in emergency surgery. Trop Doct 2011; 41 (4): 193-196. 